\title{
Phylogenetic Analysis of Hepatitis E Virus in Northwest India
}

\author{
Nidhi Subhash Chandra, ${ }^{1}$ Ramesh Roop Rai, ${ }^{2}$ and Bharti Malhotra ${ }^{1}$ \\ ${ }^{1}$ Advanced Research Lab, SMS Medical College, Jaipur, Rajasthan 302004, India \\ ${ }^{2}$ Gastroenterology Department, Fortis Escorts Hospital, Jawaharlal Nehru Marg, Malviya Nagar, Jaipur, Rajasthan 302017, India
}

Correspondence should be addressed to Nidhi Subhash Chandra, neha.jagjit@gmail.com

Received 31 May 2012; Revised 15 September 2012; Accepted 19 September 2012

Academic Editor: Yoichi Hiasa

Copyright (C) 2012 Nidhi Subhash Chandra et al. This is an open access article distributed under the Creative Commons Attribution License, which permits unrestricted use, distribution, and reproduction in any medium, provided the original work is properly cited.

\begin{abstract}
Genotyping and subtyping are important to understand epidemiology of the hepatitis E virus so as to improve control measures to prevent transmission of virus in the community. Hence, the aim of the current study was to identify the prevalent HEV genotypes in Rajasthan in acute sporadic hepatitis E cases with varying degree of liver failure. We studied hepatitis E virus (HEV) isolates from hospitalized patients in Rajasthan, western India. In a total of seventeen HEV sequences, six acute viral hepatitis, seven acute liver failure, and 4 acute- on-chronic cases were analyzed. Subtypes 1a and 1c of HEV are prevalent in Northwest India.
\end{abstract}

\section{Introduction}

Hepatitis $\mathrm{E}$ is an enterically transmitted disease that spreads through faecal contamination of drinking water. It occurs both in the form of epidemics as well as sporadic infection in developing countries $[1,2]$. It is endemic to the Indian subcontinent, where the seroprevalence rate ranges between 4 and $20 \%$. More than $60 \%$ of acute viral hepatitis cases are attributed to HEV [3]. Hepatitis E virus affects young to middle aged adults and causes high mortality in pregnant women, $20-30 \%$ as compared to $0.2-1 \%$ in general population [3]. It has been implicated as an important aetiological agent for sporadic fulminant hepatic failure (FHF) in developing countries [4].

HEV belongs to the genus Hepevirus in the family Hepeviridae and has a $7.2 \mathrm{~kb}$ positive-sense single-stranded RNA genome [5]. The HEV genome has three open-reading frames (ORFs). The ORF1, ORF2, and ORF3 encode nonstructural proteins including an RNA-dependent RNA polymerase (RdRp), a capsid protein, and a small protein that possibly induces immune suppression in HEV-infected patients, respectively $[6,7]$. Presently, HEV is classified into four major genotypes [8]. Further classification of genotypes into various subtypes was given by $\mathrm{Lu}$ et al., 2006 [9]. Genotypes 1 and 2 have been identified exclusively in humans, and genotypes 3 and 4 have been found in humans and several animal species. Genotypes 1 and 2 have been isolated in Asia, Africa, North America; genotype 4 has been identified only in Asia; and genotype 3 has been found in almost every country [10].

All parts of India have been experiencing repeated outbreaks and sporadic cases of HEV since 1955 [11-14] with genotype 1 being prevalent in the human population. With the development of knowledge about the circulation of subtypes of HEV, this study is aimed at the molecular characterization of HEV isolates to determine the most prevalent genotype in Northwest India (Rajasthan).

\section{Materials and Methods}

2.1. Patient. The present study was carried out on 585 acute hepatitis patients attending the OPD or admitted in wards of Gastroenterology Department of the SMS Medical College and Hospital Jaipur, Rajasthan a tertiary care centre, from September 2006 to December 2009. The study was approved by the institutional ethics committee and informed written consent was taken from the patients. On the basis of disease severity the study comprised three HEV-induced groups: acute viral hepatitis (AVH), acute liver failure (ALF), and acute-on-chronic liver disease (ACLF), respectively. The diagnostic criterion for AVH, ALF, and ACLF was as follows.

$\mathrm{AVH}$ is marked by appearance of jaundice with or without prodrome and raised ALT and AST levels. 
ALF is defined as the rapid development of hepatocellular dysfunction, specifically coagulopathy and mental status changes (encephalopathy) in a patient without known prior liver disease and with an illness of $<24$ weeks duration.

ACLF is defined by the Asian Pacific Association for the Study of Liver (APASL, 2008) as an acute hepatic insult manifesting as jaundice and coagulopathy, complicated within 4 weeks by ascites and/or encephalopathy in a patient with previously diagnosed or undiagnosed chronic liver disease (CLD).

Patients with stable compensated chronic liver disease, significant comorbid illnesses like coronary artery disease, renal failure, and cerebrovascular disease were excluded from the study.

2.2. Sample Collection. $10 \mathrm{~mL}$ blood samples were collected from all the cases. The serum was separated and stored at $-80^{\circ} \mathrm{C}$ taking precaution avoiding repeated freezing and thawing of the samples by aliquating them separately for serology and PCR. The clinical symptoms of the patients were recorded simultaneously and all the biochemical tests were performed.

2.3. Serology. Serum samples were screened using commercially available Micro-ELISA for markers of hepatitis E (EIAgen HEV IgM, Adaltis, Spain). The kit was coated with recombinant proteins for open-reading frames (ORFs) 1 and 2 with $98 \%$ sensitivity and specificity. ELISA was performed as per manufacturers' protocol.

2.4. Biochemical Profile. The following biochemical parameters were done for all the patients: (i) serum alanine aminotransferase (ALT), (ii) serum aspartate aminotransferase (AST), (iii) alkaline phosphatase (ALP), and (iv) total bilirubin (TB).

2.5. RNA Extraction. RNA extraction from serum of acute hepatitis E cases was done by GITC chloroform phenol method with minor modification [15].

2.6. RT-PCR. Extracted RNA was subjected for cDNA synthesis. cDNA synthesis was carried out using MuLV RT enzyme, reverse primer $(20 \mathrm{pmol} / \mathrm{mL})$ (external antisense: 5' -CCG AAT TCA AAG GCA TCC ATG GTG TTT GAG AAT GAC- $\left.3^{\prime}\right)$ (Promega), RNase out (20 U/ $\mu \mathrm{L}$, invitrogen), $0.1 \mathrm{M}$ $\mathrm{DTT}$, and $5 \mu \mathrm{L}$ templates at $42^{\circ} \mathrm{C}$ for one hour.

After cDNA synthesis PCR amplification was carried out using the specific previously validated primers selected from nonstructural ORF1 region (Gene Bank accession no. M32400) [1]. The primers used were external sense: $5^{\prime}$ - CCG GAT CCA CAC ACA TCT GAG CTA CAT TCG TGA GCT3', external anti-sense: 5' - CCG AAT TCA AAG GCA TCC ATG GTG TTT GAG AAT GAC- 3', internal sense: 5' - GGA ATT CGA CTC CAC CCA GAA TTA CTT- 3', and internal anti-sense 5' - GGA ATT CAC AGC CGG CGA TCA GGA CAG- $3^{\prime}$. These two sets of primers were designed to produce 343 bp segment of ORF1 region [1].

The thermal cycling conditions were as follows: initial denaturation $94^{\circ} \mathrm{C}$ for 5 minutes followed by 30 cycles of denaturation for 30 seconds at $94^{\circ} \mathrm{C}$, annealing for 30 seconds at $59^{\circ} \mathrm{C}$, and extension for 30 seconds at $72^{\circ} \mathrm{C}$, as well as final extension for 7 minutes at $72^{\circ} \mathrm{C}$. Positive and negative control was included in every reaction to rule out false positive and negative.

2.7. DNA Sequencing. Amplified final PCR products (343 bp of RdRp region) were separated in a $1.5 \%$ gel. The expected bands were excised from the gel and purified with a QIA quick gel extraction kit (Qiagen, Hilden, Germany). The purified DNA were subjected to sequencing PCR using big dye terminator ready reaction mixture, reverse primer (3.2 pmoles $/ \mu \mathrm{L}$ ) at thermal cycling conditions: 25 cycles of denaturation $94^{\circ} \mathrm{C}$ for 10 seconds, annealing $55^{\circ} \mathrm{C}$ for 5 seconds and extension $60^{\circ} \mathrm{C}$ for 4 minutes. Cycle sequencing PCR product was purified by adding 0.1 volume of $3 \mathrm{M}$ sodium acetate $(\mathrm{pH}=4.5)$ and 2.5 volume of absolute alcohol and dissolved in $25 \mu \mathrm{L}$ of template suspension reagent (TSR) and heated at $95^{\circ} \mathrm{C}$ for 5 minutes and snap-chilled to denature the DNA. Samples were transferred in fresh tubes, and closed with septa. These samples were loaded on sample tray. The sample was run through performance-optimized polymer (POP6) and electrophoreses at $12.1 \mathrm{kv}$ for 3 hours in 1 Xgenetic analyser buffer on ABI prism 310 sequencer.

2.8. Phylogenetic Analysis. Amplicon sequences of $\mathrm{HEV}$ RdRp region were compared to an online database for the best possible match using the BLAST (Basic Local Alignment Search Tool) program of National center for Biotechnology information (http://www.ncbi.nlm.nih.gov/) and CLUSTAL$\mathrm{X}$ version 2.0. The evolutionary history was inferred using the Neighbor-Joining method [16]. The optimal tree with the sum of branch length $=1.92628740$ is shown. The percentage of replicate trees in which the associated taxa clustered together in the bootstrap test (1000 replicates) is shown next to the branches [17]. The tree is drawn to scale, with branch lengths in the same units as those of the evolutionary distances used to infer the phylogenetic tree. The evolutionary distances were computed using the Kimura 2-parameter method [18] and are in the units of the number of base substitutions per site. Codon positions included were $1 s t+2 \mathrm{nd}+3 \mathrm{rd}+$ noncoding. All positions with less than 95\% site coverage were eliminated, that is, fewer than 5\% alignment gaps; missing data and ambiguous bases were allowed at any position. There were a total of 189 positions in the final dataset. Phylogenetic analyses were conducted in MEGA4 [19].

Subgenomic sequences of known HEV genotypes were retrieved from NCBI database (http://www.ncbi.nlm.nih .gov/nuccore/). Only those sequences, which had our target region of HEV RdRp, were taken for phylogenetic analysis.

\section{Statistical Analysis}

For data management and statistical analysis, SPSS-10 software (SPSS Inc., Chicago, IL, USA) was used. Baseline laboratory markers were expressed as mean values with standard deviation. Difference between AVH, ALF, and ACLF with respect to various liver function tests was calculated 
TABLE 1: Characteristic features of the patients.

\begin{tabular}{lccc}
\hline Parameter & AVH & ALF & SAHF \\
\hline No. of cases & 100 & 75 & 30 \\
Male female & $63: 37$ & $54: 21$ & $21: 9$ \\
$\begin{array}{l}\text { No. of pregnant } \\
\text { females }\end{array}$ & 11 & 16 & 0 \\
Age (yrs) & $23.1 \pm 4.65$ & $24.67 \pm 3.37$ & $27.75 \pm 9.31$ \\
Height (cms) & $151.43 \pm 5.06$ & $150.30 \pm 4.23$ & $154.92 \pm 4.75$ \\
Weight (Kg) & $51.05 \pm 5.76$ & $46.69 \pm 4.36$ & $51.61 \pm 6$ \\
PT (seconds) & $15.1 \pm 1.9$ & $29.8 \pm 12.3$ & $14 \pm 0.81$ \\
\hline
\end{tabular}

PT: prothrombin time.

Data expressed as mean \pm SD (range).

TABLE 2: Clinical features of the patients.

\begin{tabular}{lccc}
\hline Parameter & AVH (100) & ALF (75) & SAHF (30) \\
\hline Fever & 42.8 & 77.7 & 66.6 \\
Pruritus & 66.6 & 22.2 & 33.3 \\
Anorexia & 57.1 & 66.6 & 100 \\
Pedal edema & 0.0 & 77.7 & 68.2 \\
Ascites & 63.3 & 72.1 & 67.3 \\
\hline
\end{tabular}

Data expressed as percentage (\%).

using the ANOVA (analysis of variance). $P$ value of less than 0.05 was considered significant.

\section{Results}

In the study, a total of 585 acute hepatitis cases were included. Amongst these 205 (35.04\%) were found to be positive for IgM anti-HEV antibodies. These were grouped into 100 patients with acute viral hepatitis $(\mathrm{AVH}), 75$ with acute liver failure (ALF), and 30 with acute on chronic liver failure (ACLF). Age presentation, sex distribution, and characteristic features of different groups were as shown in Table 1. Maximum numbers of cases of HEV were seen in the age group 15-40 years. Out of 67 consecutive females, $27(40.16 \%)$ were pregnant. The mortality rate in pregnant females was $6 / 27(22.22 \%)$ and in nonpregnant females was $1 / 40(2.5 \%)$. There was no mortality in 100 patients of AVH, while 9/75 (12\%) ALF patients and 2/30 (6.67\%) SAHF patients died.

Variation was observed in the different groups with respect to clinical symptoms like fever, pruritus, anorexia, and pedal edema as shown in Table 2. The age and LFT profile (AST, ALT, and ALP) was significantly higher in ALF cases than SAHF and AVH but no significant difference was obtained in total serum bilirubin as shown in Table 3.

Due to the transient viremic nature of HEV infection, 80/205 samples were selected (within 1 week of the illness) for HEV RNA detection by nested reverse transcriptase polymerase chain reaction (nRT-PCR). 47/80 (58.75\%) were positive for HEV-RNA. Only 17 from different groups were selected for sequence analysis.

The amplification products of RdRp region of ORF1 (343 nt) from $6 \mathrm{AVH}$ patients, 7 ALF patients, and 4 acute on chronic patients were subjected for sequence analysis and submitted to GenBank with accession nos. FJ231471, FJ231472, FJ231473, FJ231474, FJ231475, FJ231476, FJ231477, FJ231478, FJ231479, FJ231480, FJ231481, FJ231482, FJ231483, FJ231484, FJ231485, FJ231486, FJ231487. Gene sequences of the present isolates along with standard strains from different geographical areas were used for the construction of the phylogenetic tree.

All $17 \mathrm{HEV}$ isolates belonged to genotype 1 with $>98 \%$ sequence homology. Figure 1 shows the phylogenetic tree constructed for the 17 new sequences and their closest matching sequences in GenBank. To further classify the subtype, we included some well-characterized subtypes for phylogenetic analysis.

Figure 1 shows that among the 17 ( 6 AVH with accession nos. FJ231474, FJ231475, FJ231477, FJ231480, FJ231481, FJ231482; 7 ALF with accession nos. FJ231472, FJ231473, FJ231476, FJ231483, FJ231484, FJ231485, FJ231486; remaining 4 the accession nos. belong to ACLF) HEV isolates 12 belonged to genotype $1 \mathrm{a}$ and 5 belonged to genotype 1c. The sequences of these $17 \mathrm{HEV}$ isolates shared $91.3 \%-$ 98.5\% sequence homology among themselves. All AVH and ACLF isolates belonged to genotype 1a and two ALF isolates belonged to genotype $1 \mathrm{a}$ and the remaining five were clustered with genotype 1c. HEV isolates which belonged to genotype 1c had 90.1\%-93.5\% sequence homology with subtype $1 \mathrm{c}$ and $\mathrm{HEV}$ isolates which belonged to genotype 1a had 91.5\%-94.2\% sequence homology with subtype 1a. There was a high degree of variability found between genotypes 3 and 4 , with a divergence of $31.2 \%$ and $30.1 \%$, respectively.

Patients with genotype 1c had significantly higher peak alanine aminotransferase levels (median 2930 IU/L, interquartile range $1837-3763$ versus $1324 \mathrm{IU} / \mathrm{L}, 945-2317 ; P=$ 0.01 ) than genotype $1 \mathrm{a}$ and the prothrombin time was lower in the genotype 1c patients (61\%, 42-77 versus 84\%, 70-96; $P=0.05)$.

\section{Discussion}

Up to now, divergent $\mathrm{HEV}$ sequences have been reported from many countries and fall into 4 major genotypes, namely, genotypes $1,2,3$, and 4 [8]. Based upon nucleotide differences, it is proposed that five, two, ten, and seven subtypes for HEV genotypes 1, 2, 3, and 4 designated respectively [9]. However, inspite of the genomic diversity of $\mathrm{HEV}$, studies conducted so far $[20,21]$ indicate that all strains identified till date comprise a single serotype $[9,22]$.

It is reported that genotypes 1 and 4 continue to circulate in humans and pigs, respectively, from India [23, 24]. However, identification of two different isolates from the same region of Japan indicated that there could be significant diversity between strains from the same region [25]. Subsequently diversity was found between various isolates from Argentina, Austria [26, 27], Spain [28], China, and Taiwan $[29,30]$.

Growing reports suggest that different HEV genotypes and subtypes play important role in disease severity. Genotypes 1 and 2 have similar epidemiological and sporadic 


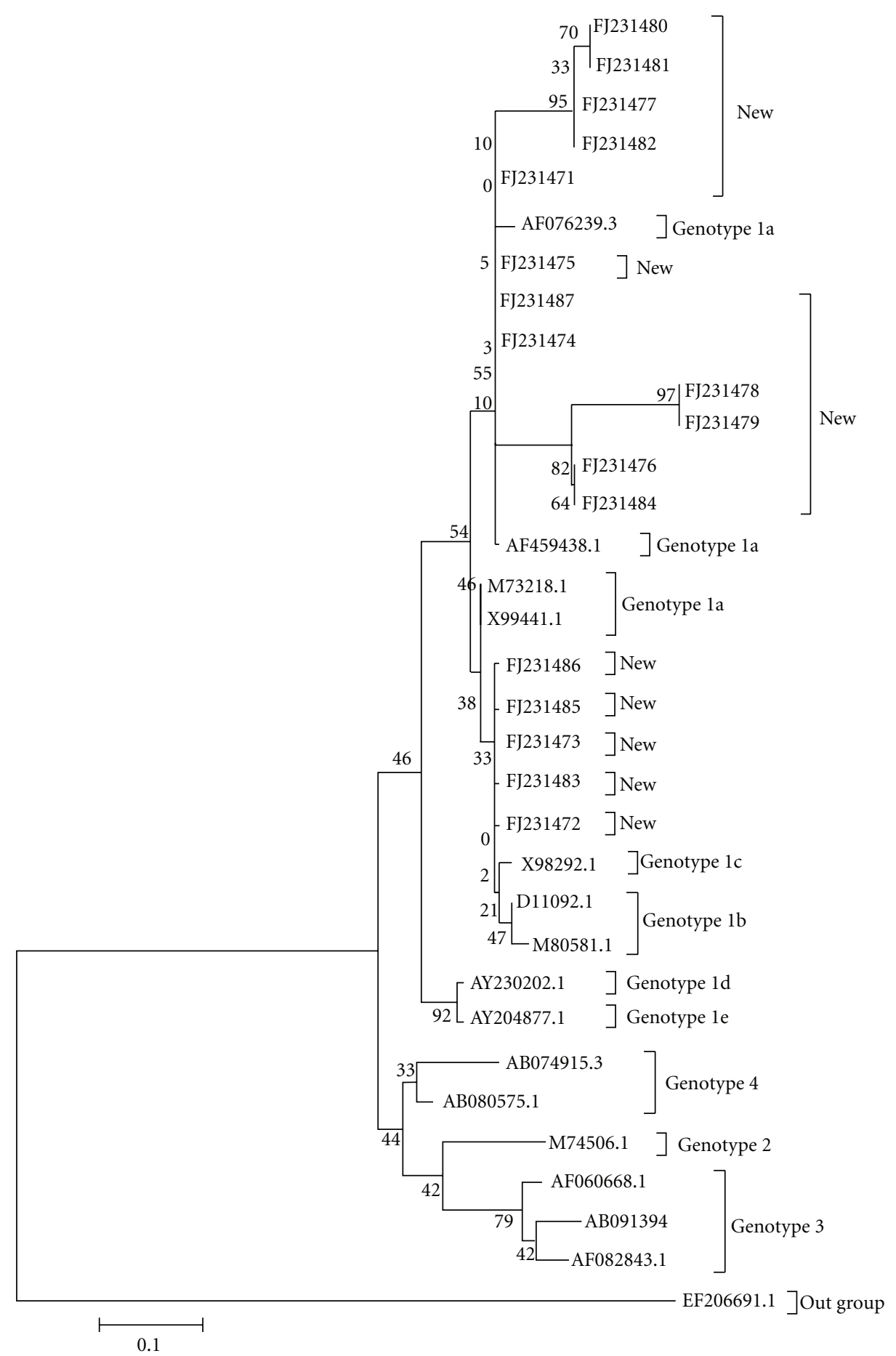

FIGURE 1: Molecular phylogenetic analysis by neighbor-joining method; phylogenetic tree analysis of 343 bp fragments from 17 HEV isolates obtained in the studied population and standard genotypes from NCBI database.

features and can result in acute hepatitis, acute liver failure, and acute-on-chronic liver failure while genotypes 3 and 4 were normally considered to cause acute, self-limiting illness followed by a complete recovery. Thus in human genotypes 3 and 4 seem to be less virulent than genotypes 1 and 2 [31] and do not cause severe liver diseases [32]. HEV genotypes may affect the effectiveness of viral transmission and, in turn, the severity of HEV, associated hepatitis; therefore we classified patients into three groups on the bases of disease severity.

Genotype 1 of human HEV is most prevalent in Asian countries. Nevertheless, several genotypes circulate in the neighbouring countries, such as China, Thailand, or Vietnam, where genotypes 3 and 4 have also been identified 
TABLE 3: Different biochemical parameters.

\begin{tabular}{lcccc}
\hline Parameter & AVH & ALF & SAHF & $P$ value \\
\hline Hb $(\mathrm{g} \%)$ & $28 \pm 10.4$ & $34.5 \pm 9.7$ & $37.5 \pm 14.5$ & 0.013 \\
AST $(\mathrm{IU} / \mathrm{mL})$ & $394.8 \pm 440.6$ & $905.9 \pm 590.3$ & $584.2 \pm 644.8$ & 0.000 \\
ALT $(\mathrm{IU} / \mathrm{mL})$ & $540.1 \pm 551.9$ & $1067.8 \pm 642$ & $749.2 \pm 750.8$ & 0.035 \\
S. bil $(\mathrm{mg} / \mathrm{dL})$ & $6.07 \pm 4.2$ & $9.3 \pm 5.4$ & $6.5 \pm 4$ & 0.060 \\
ALP $(\mathrm{IU} / \mathrm{mL})$ & $751.1 \pm 612.8$ & $1272.2 \pm 710.6$ & $822.5 \pm 750.1$ & 0.000 \\
\hline
\end{tabular}

Data expressed as mean $\pm \mathrm{SD}$.

$P$ value $<0.05$ consider as statistically significant.

from human and swine infections. Studies demonstrated that human and swine HEVs from Western and Southern India belong to different genotypes; genotype 1 circulates in humans whereas genotype 4 in pigs [33-35] and the majority of the Indian isolates belong to subtypes $1 \mathrm{a}, 1 \mathrm{~b}$, $1 \mathrm{c}$, and $1 \mathrm{~d}$, though HEV genotypes appear to be segregated geographically [36]. Single Ind-FHF isolates were studied to form genotype ID. Although all other Indian isolates were from either western or southern parts of India, the exact location of isolation of isolate Ind-FHF is not known [36]. In a recent report from North India subtypes $1 \mathrm{a}$ and $1 \mathrm{c}$ are prevalent with the subtype 1c showing a trend towards fulminancy [37]. This diversity of genotypes and subtypes is useful in understanding epidemiological phenomena such as geographical spread of the virus or the transmission in the community.

In the present study, the strains phylogenetically clustered into genotype 1 and formed two subgroups "a" and "c," sharing $91.5 \%-94.2 \%$ and $90.1 \%-93.5 \%$ homology with intersubgroup and $79.5-85.3 \%, 80.1-84.8 \%$, and $78.3-80 \%$ intrasubgroup identity homology with subgroup " $\mathrm{b}$ ", "d," and "e," respectively. This suggests that in Northwest India, different subgroups may be present. Interestingly, we also observed that the patients with genotype $1 \mathrm{c}$ tend to have more clinical manifestation than those with genotype 1a infection.

\section{Conclusion}

In conclusion, the circulating genotypes and subtypes have important epidemiological implication. The present study indicates that genotype 1 is the main prevalent type of the genotypes in humans in North West India with subgroup "a" and "c." AVH and ALF patients have different subtypes "a" and "c," respectively, which raises our insight on the molecular basis of HEV disease severity.

\section{Conflict of Interests}

The authors declare that they have no conflict interests.

\section{Acknowledgments}

The authors are thankful to the Principal and Controller of SMS Medical College for providing lab facilities. The authors would like to acknowledge ICMR for their financial support as SRF (ECD-1/598/08) and they are also thankful to the Department of Gastroenterology for providing samples.

\section{References}

[1] S. Jameel, H. Durgapal, C. M. Habibullah, M. S. Khuroo, and S. K. Panda, "Enteric non-A, non-B hepatitis: epidemics, animal transmission, and hepatitis E virus detection by the polymerase chain reaction," Journal of Medical Virology, vol. 37, no. 4, pp. 263-270, 1992.

[2] G. R. Reyes, M. A. Purdy, J. P. Kim et al., "Isolation of a cDNA from the virus responsible for enterically transmitted non-A, non-B hepatitis," Science, vol. 247, no. 4948, pp. 1335-1339, 1990.

[3] V. Chandra, S. Taneja, M. Kalia, and S. Jameel, "Molecular biology and pathogenesis of hepatitis E virus," Journal of Biosciences, vol. 33, no. 4, pp. 451-464, 2008.

[4] S. K. Nanda, K. Yalcinkaya, A. K. Panigrahi, S. K. Acharya, S. Jameel, and S. K. Panda, "Etiological role of hepatitis E virus in sporadic fulminant hepatitis," Journal of Medical Virology, vol. 42, no. 2, pp. 133-137, 1994.

[5] S. K. Panda, D. Thakral, and S. Rehman, "Hepatitis E virus," Reviews in Medical Virology, vol. 17, no. 3, pp. 151-180, 2007.

[6] A. W. Tam, M. M. Smith, M. E. Guerra et al., "Hepatitis E virus (HEV): molecular cloning and sequencing of the full-length viral genome," Virology, vol. 185, no. 1, pp. 120-131, 1991.

[7] S. Tyagi, M. Surjit, and S. K. Lal, "The 41-amino-acid Cterminal region of the hepatitis E virus ORF3 protein interacts with bikunin, a kunitz-type serine protease inhibitor," Journal of Virology, vol. 79, no. 18, pp. 12081-12087, 2005.

[8] G. G. Schlauder and I. K. Mushahwar, "Genetic heterogeneity of hepatitis E virus," Journal of Medical Virology, vol. 65, no. 2, pp. 282-292, 2001.

[9] L. Lu, C. Li, and C. H. Hagedorn, "Phylogenetic analysis of global hepatitis E virus sequences: genetic diversity, subtypes and zoonosis," Reviews in Medical Virology, vol. 16, no. 1, pp. 5-36, 2006.

[10] H. Ning, Z. Niu, R. Yu, P. Zhang, S. Dong, and Z. Li, "Identification of genotype 3 hepatitis $E$ virus in fecal samples from a pig farm located in a Shanghai suburb," Veterinary Microbiology, vol. 121, no. 1-2, pp. 125-130, 2007.

[11] S. Kumar, R. K. Ratho, Y. K. Chawla, and A. Chakraborti, “The incidence of sporadic viral hepatitis in North India: a preliminary study," Hepatobiliary and Pancreatic Diseases International, vol. 6, no. 6, pp. 596-599, 2007.

[12] S. Kumar, R. K. Ratho, Y. K. Chawla, and A. Chakraborti, "Virological investigation of a hepatitis E epidemic in North India," Singapore Medical Journal, vol. 47, no. 9, pp. 769-773, 2006. 
[13] S. Bali, S. S. Kar, S. Kumar, R. K. Ratho, R. K. Dhiman, and R. Kumar, "Hepatitis E epidemic with bimodal peak in a town of north India.," Indian Journal of Public Health, vol. 52, no. 4, pp. 189-199, 2008.

[14] P. Prinja, K. Subrat, G. M. M. Reddy, R. K. Ratho, and K. Rajesh, "Investigation of viral hepatitis e outbreak in a town in Haryana," Journal of Communicable Diseases, vol. 40, no. 4, pp. 249-254, 2008.

[15] P. Chomczynski and N. Sacchi, "Single-step method of RNA isolation by acid guanidinium thiocyanate-phenol-chloroform extraction," Analytical Biochemistry, vol. 162, no. 1, pp. 156-159, 1987.

[16] N. Saitou and M. Nei, "The neighbor-joining method: a new method for reconstructing phylogenetic trees.", Molecular Biology and Evolution, vol. 4, no. 4, pp. 406-425, 1987.

[17] J. Felsenstein, "Confidence limits on phylogenies: an approach using the bootstrap," Evolution, vol. 39, no. 4, pp. 783-791, 1985.

[18] M. Kimura, "A simple method for estimating evolutionary rates of base substitutions through comparative studies of nucleotide sequences," Journal of Molecular Evolution, vol. 16, no. 2, pp. 111-120, 1980.

[19] K. Tamura, J. Dudley, M. Nei, and S. Kumar, "MEGA4: molecular evolutionary genetics analysis (MEGA) software version 4.0," Molecular Biology and Evolution, vol. 24, no. 8, pp. 1596-1599, 2007.

[20] V. A. Arankalle, M. S. Chadha, S. A. Tsarev et al., "Seroepidemiology of water-borne hepatitis in India and evidence for a third enterically-transmitted hepatitis agent," Proceedings of the National Academy of Sciences of the United States of America, vol. 91, no. 8, pp. 3428-3432, 1994.

[21] D. L. Thomas, P. O. Yarbough, D. Vlahov et al., "Seroreactivity to hepatitis E virus in areas where the disease is not endemic," Journal of Clinical Microbiology, vol. 35, no. 5, pp. 1244-1247, 1997.

[22] R. H. Purcell, "Hepatitis viruses: changing patterns of human disease.," Proceedings of the National Academy of Sciences of the United States of America, vol. 91, no. 7, pp. 2401-2406, 1994.

[23] V. A. Arankalle, L. P. Chobe, M. V. Joshi, M. S. Chadha, B. Kundu, and A. M. Walimbe, "Human and swine hepatitis E viruses from western India belong to different genotypes," Journal of Hepatology, vol. 36, no. 3, pp. 417-425, 2002.

[24] V. A. Arankalle, K. S. Lole, T. M. Deshmukh, L. P. Chobe, and S. S. Gandhe, "Evaluation of human (genotype 1) and swine (genotype 4)-ORF2-based ELISAs for anti-HEV IgM and IgG detection in an endemic country and search for type 4 human HEV infections," Journal of Viral Hepatitis, vol. 14, no. 6, pp. 435-445, 2007.

[25] H. Mizuo, K. Suzuki, Y. Takikawa et al., "Polyphyletic strains of hepatitis E virus are responsible for sporadic cases of acute hepatitis in Japan," Journal of Clinical Microbiology, vol. 40, no. 9, pp. 3209-3218, 2002.

[26] H. C. Worn, G. G. Schlauder, H. Wurzer, and I. K. Mushahwar, "Identification of a novel variant of hepatitis E virus in Austria: sequence, phylogenetic and serological analysis," Journal of General Virology, vol. 81, no. 12, pp. 2885-2890, 2000.

[27] G. G. Schlauder, G. J. Dawson, J. C. Erker et al., "The sequence and phylogenetic analysis of a novel hepatitis E virus isolated from a patient with acute hepatitis reported in the United States," Journal of General Virology, vol. 79, no. 10, pp. 447456, 1998.

[28] S. Pina, M. Buti, M. Cotrina, J. Piella, and R. Girones, "HEV identified in serum from human with acute hepatitis and sewage of animal origin in Spain," Journal of Hepatology, vol. 33, no. 5, pp. 826-833, 2000.

[29] R. Huang, N. Nakazono, K. Ishii, O. Kawamata, R. Kawaguchi, and Y. Tsukada, "II. Existing variations on the gene structure of hepatitis E virus strains from some regions of China," Journal of Medical Virology, vol. 47, no. 4, pp. 303-308, 1995.

[30] Y. Wang, H. Zhang, R. Ling, H. Li, and T. J. Harrison, "The complete sequence of hepatitis $\mathrm{E}$ virus genotype 4 reveals an alternative strategy for translation of open reading frames 2 and 3," Journal of General Virology, vol. 81, no. 7, pp. 16751686, 2000.

[31] R. H. Purcell and S. U. Emerson, "Hepatitis E: an emerging awareness of an old disease," Journal of Hepatology, vol. 48, no. 3, pp. 494-503, 2008.

[32] S. K. Acharya and S. K. Panda, "Editorial: hepatitis E: water, water everywhere-now a global disease," Journal of Hepatology, vol. 54, no. 1, pp. 9-11, 2011.

[33] V. A. Arankalle, L. P. Chobe, A. M. Walimbe, P. N. Yergolkar, and G. P. Jacob, "Swine HEV infection in South India and phylogenetic analysis (1985-1999)," Journal of Medical Virology, vol. 69, no. 3, pp. 391-396, 2003.

[34] L. P. Chobe, K. S. Lole, and V. A. Arankalle, "Full genome sequence and analysis of Indian swine hepatitis E virus isolate of genotype 4," Veterinary Microbiology, vol. 114, no. 3-4, pp. 240-251, 2006.

[35] N. Begum, S. K. Polipalli, S. A. Husain, and P. Kar, "Molecular analysis of swine hepatitis E virus from north India," Indian Journal of Medical Research, vol. 132, no. 11, pp. 504-508, 2010.

[36] V. A. Arankalle, S. Paranjape, S. U. Emerson, R. H. Purcell, and A. M. Walimbe, "Phylogenetic analysis of hepatitis E virus isolates from India (1976-1993)," Journal of General Virology, vol. 80, no. 7, pp. 1691-1700, 1999.

[37] S. K. Pujhari, S. Kumar, R. K. Ratho, Y. K. Chawla, and A. Chakraborti, "Phylogenetic analysis and subtyping of acute and fulminant strains of hepatitis E virus isolates of North India with reference to disease severity," Archives of Virology, vol. 155, no. 9, pp. 1483-1486, 2010. 


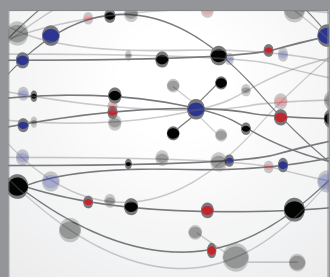

The Scientific World Journal
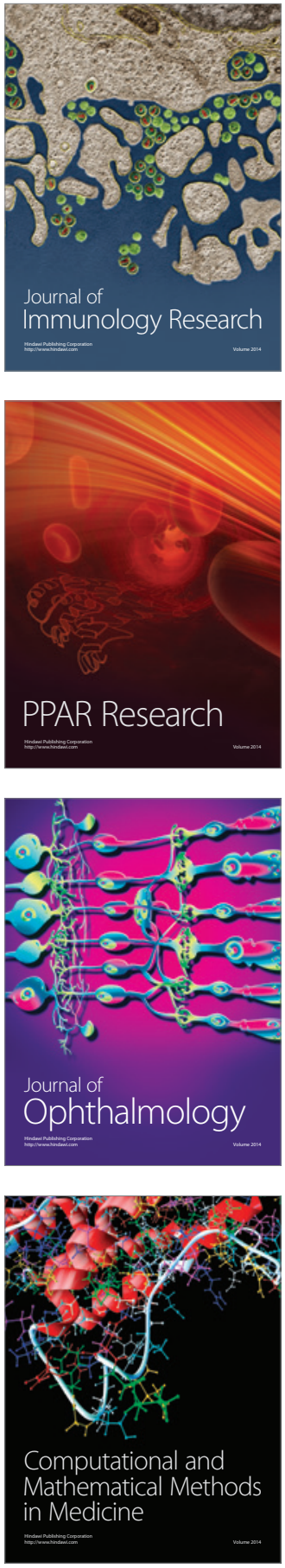

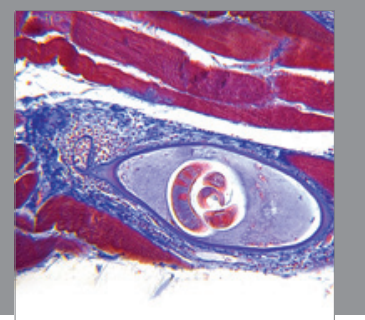

Gastroenterology

Research and Practice
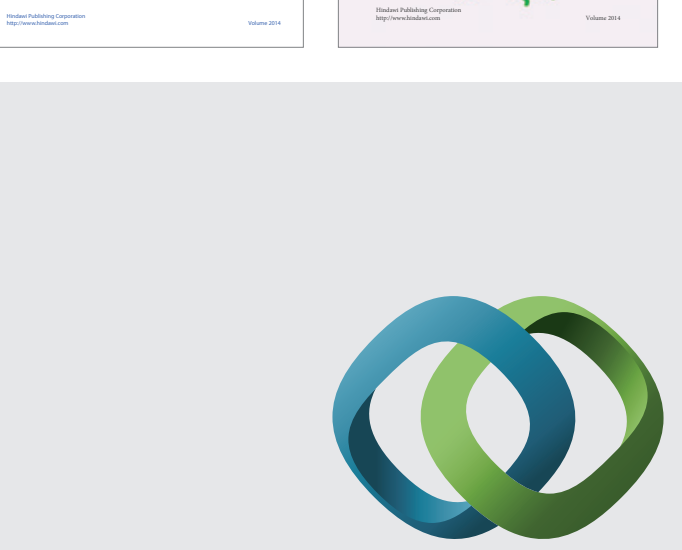

\section{Hindawi}

Submit your manuscripts at

http://www.hindawi.com
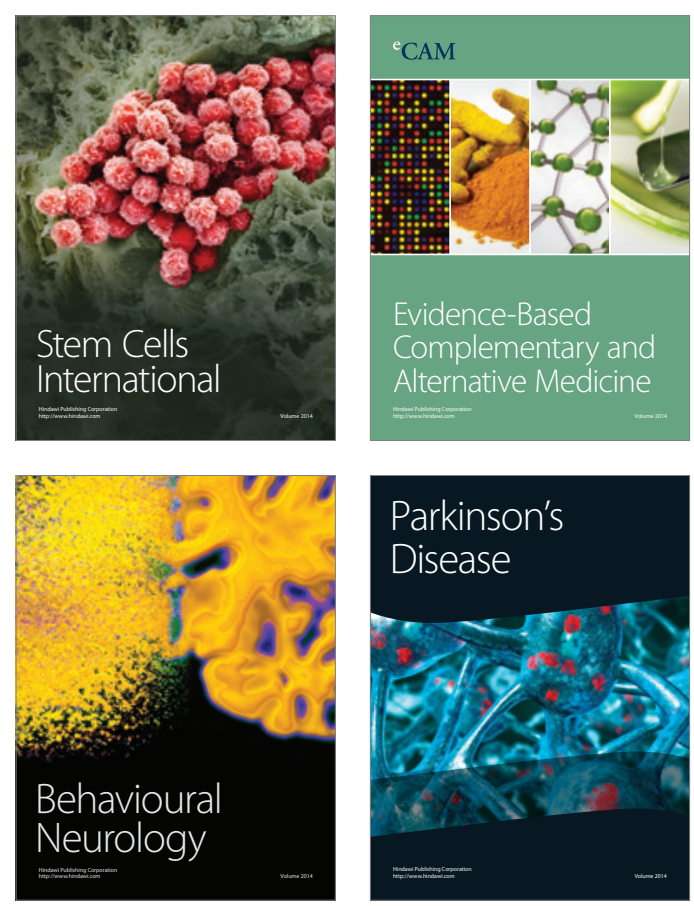

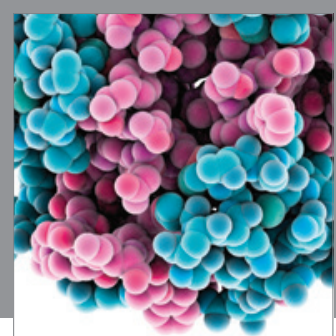

Journal of
Diabetes Research

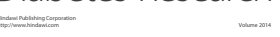

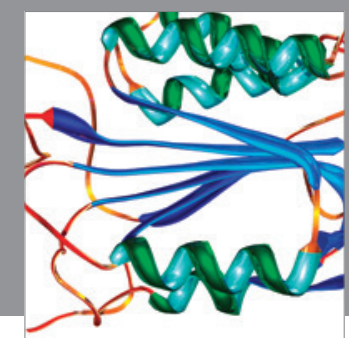

Disease Markers
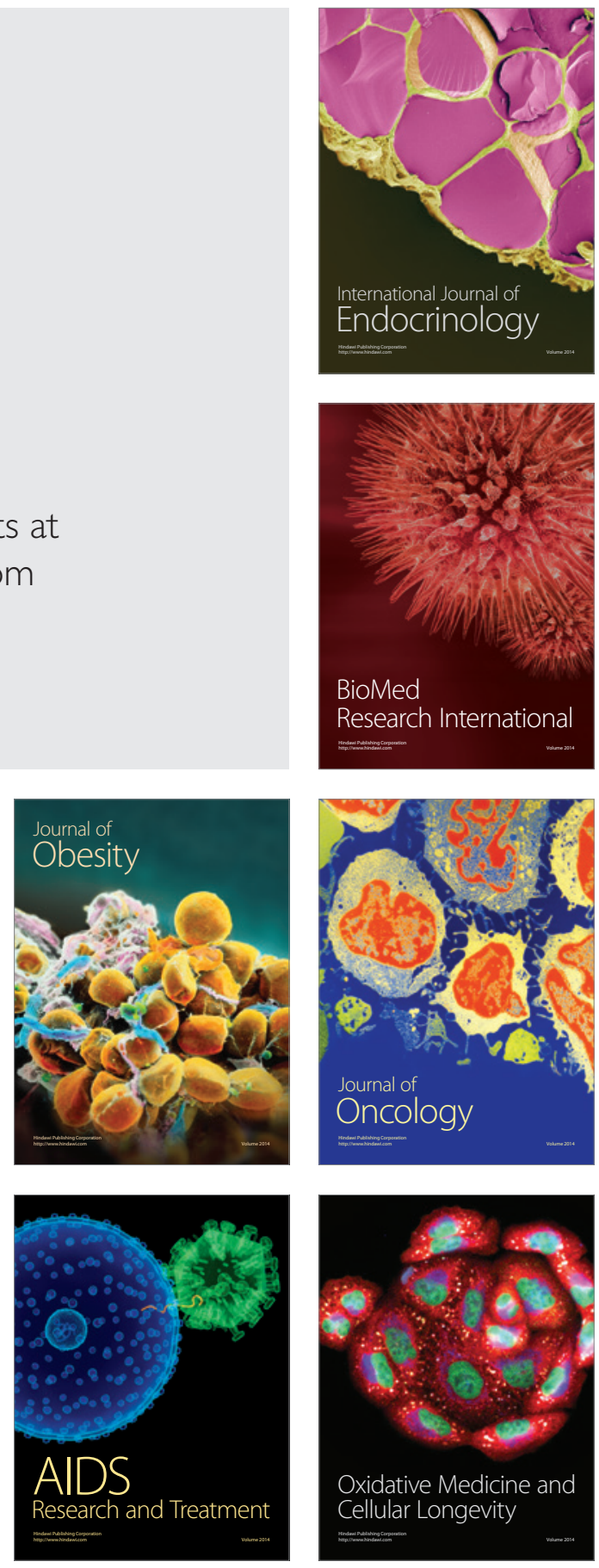